\title{
Dominantly inherited cleft lip and palate in two families
}

\author{
K TEMPLE*, M CALVERT $\dagger$, D PLINT†, E THOMPSON*, AND \\ M PEMBREY*
}

From ${ }^{*}$ the Department of Paediatric Genetics, Institute of Child Health, London WC1N 1EH; and the Dental Department, The Hospitals for Sick Children, Great Ormond Street, London WC1.

SUMmaRY Two families with non-syndromic cleft lip and cleft palate are described. The linear pattern of inheritance through several generations is difficult to explain by conventional multifactorial models. The pedigrees strengthen the suggestion that a dominantly inherited mutation exists with a major influence on clefting of the lip and palate alone.

Cleft lip with or without cleft palate has an incidence in the UK of approximately 1 per 1000 livebirths. Large family studies have shown that the incidence is much higher in relatives of affected probands. ${ }^{1-6}$

Carter $e t$ al $^{1}$ in 1982 found that the offspring and sib risk of an affected subject were both approximately $3 \%$, that is, 30 times the birth incidence. He also found a $4 \%$ risk for the offspring of probands who themselves had an affected parent, but his numbers were small $(1 / 24)$. Carter argued that a multifactorial model of inheritance best explained these findings and felt that a single gene was unlikely to make a major contribution to susceptibility to the condition.

We describe two unusual families with three and possibly four generations of subjects affected with cleft lip and cleft palate who were referred for genetic counselling within the same year. Three generations were examined in detail and no associated clinical features were found to include them in known dominantly inherited cleft lip syndromes.

\section{Case reports}

\section{FAMILY 1}

The pedigree is shown in fig 1 . The proband (IV.2, fig 2) asked to be referred for genetic advice after recall by the Dental Department as part of a study on surgical correction of maxillary hypoplasia. He was born on 10.2.64 with a cleft of the left lip, alveolus, and hard and soft palates. These were surgically corrected at four and 14 months of age respectively. On examination these findings were

Received for publication 1 June 1988.

Revised version accepted for publication 7 November 1988 confirmed. Dental health was poor but no hypodontia or lip pits were noted. Routine blood lymphocyte culture showed a normal male karyotype. The rest of the examination was normal.

III.1 was born on 28.4 .39 (fig 3). Examination showed a repaired left sided cleft lip and palate. Both the hard and soft palates were involved, but the alveolus remained intact. There was no hypodontia and good alignment of teeth. No lip pits were $\frac{\mathbb{Q}}{\mathbb{2}}$ present and the rest of the examination was normal.

II. 2 was born on 30.7 .08 (fig 4). A right sided cleft of the lip, alveolus, and hard and soft palates were noted at birth. Surgical repair had been successful

I

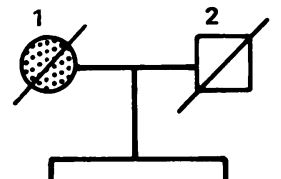

II
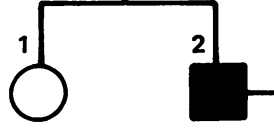

III

IV

FIG 1 Pedigree of family 1. (Shaded symbol represents a family member reported to be affected.) 


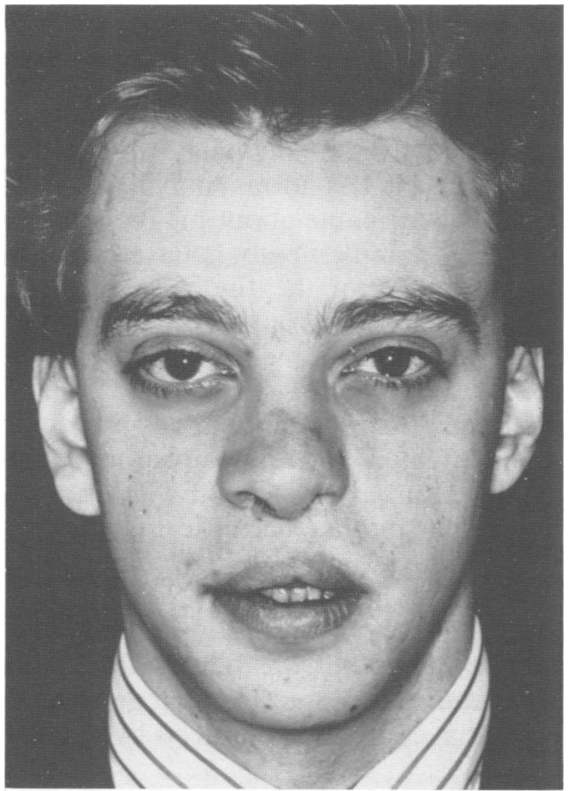

FIG 2 IV.2, family 1 showing repair of left sided cleft lip.

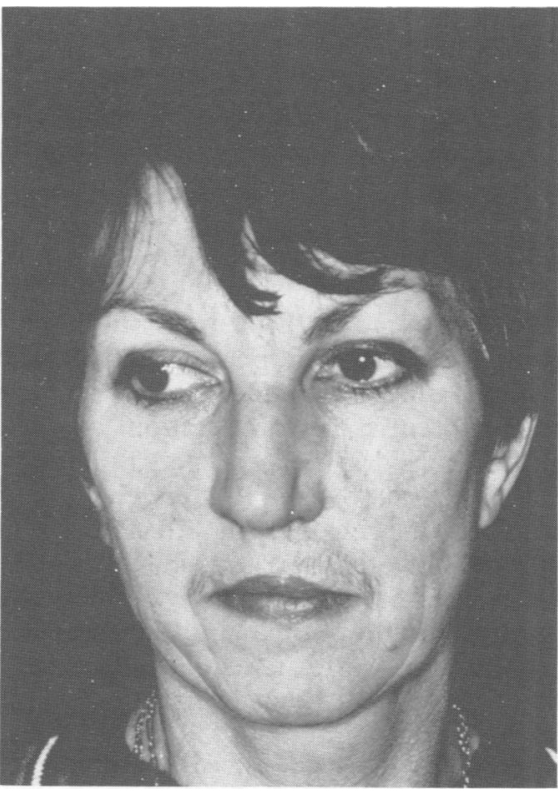

FIG 3 III.1, family 1 showing repair of right sided cleft lip.

and was confirmed on examination. Again no lip pits were present.

I.1 was born on 16.12.1877. Little information is available about this lady. The family rarely discussed cleft lip although her granddaughter can remember her admitting that she too had had a cleft lip like her son. She is described as having a red scar to one side of the midline in the upper lip extending to the base of the nose. She is thought to have had no cleft palate or lip pits. Her sibs and parents were normal.

FAMILY 2

The pedigree is shown in fig 5 . The proband (III.1) was referred for genetic counselling by his general practitioner. He was born on 25.6 .58 with a right sided cleft of the lip and hard and soft palates. These have been repaired. He now has marked midfacial

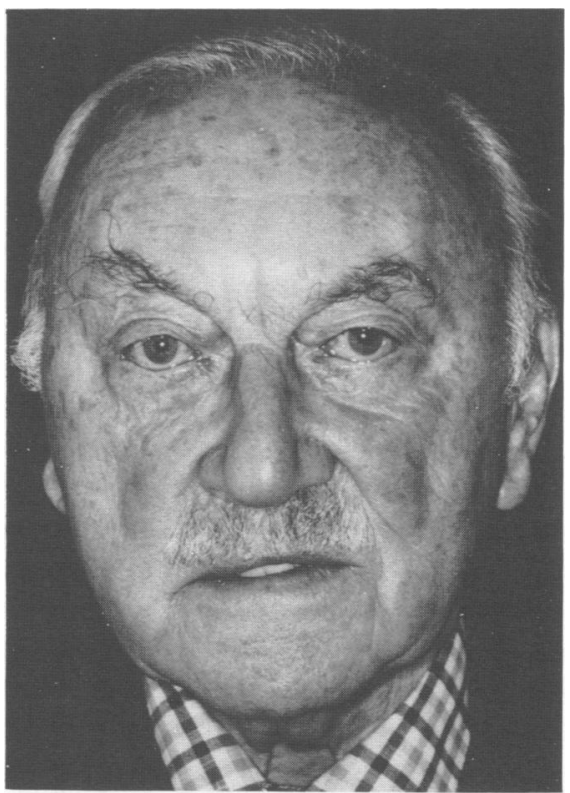

FIG 4 II.2, family 1 showing left sided scar from cleft lip repair.

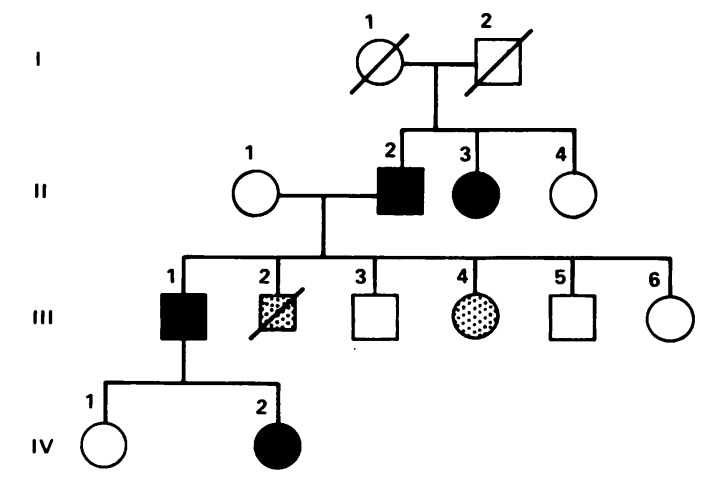

FIG 5 Pedigree of family 2. (Shaded symbols represent family members reported to be affected.) 
hypoplasia but dental health and occlusion are good. Chromosomes are normal.

IV. 2 was born on 23.7 .87 (fig 6). She was found at birth to have a severe bilateral cleft lip, alveolus, and palate. These have been recently closed success-

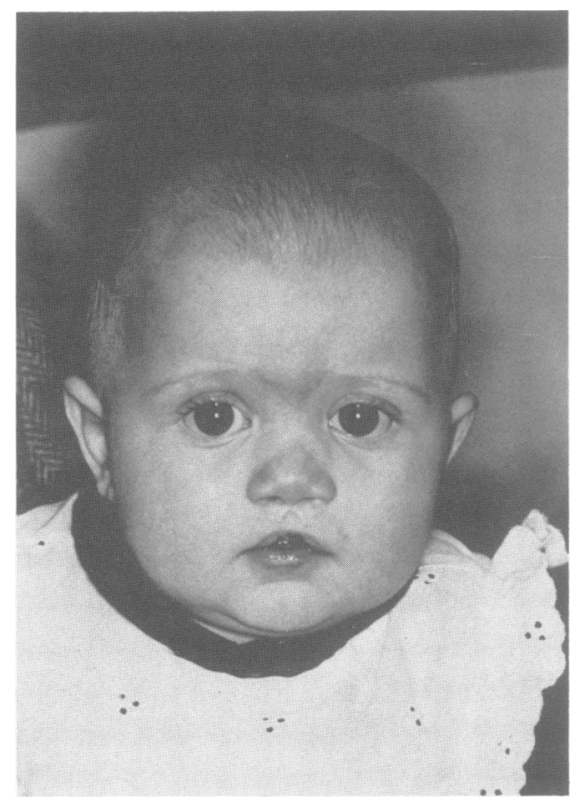

FIG 6

IV.2, family 2 showing repair of bilateral cleft lip.

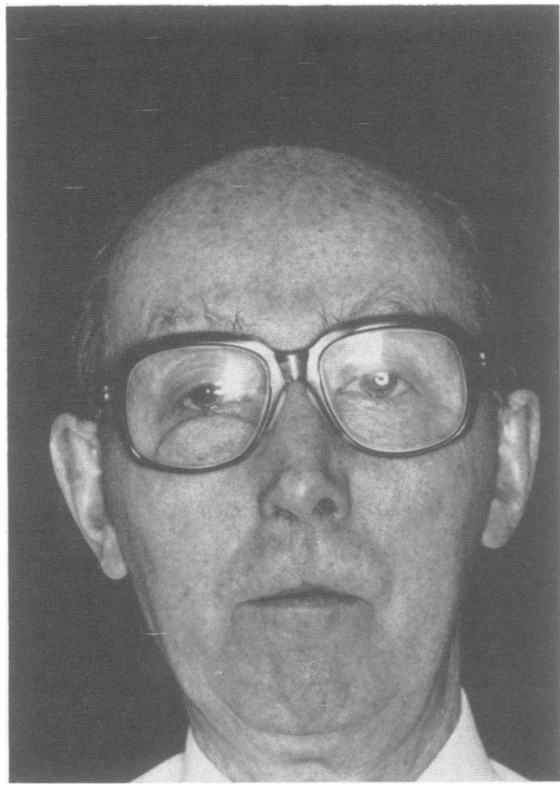

FIG 7 II.2, family 2 showing repair of right sided cleft lip. fully. Development and hearing are otherwise $\stackrel{\mathbb{D}}{?}$ normal.

II. 2 was born on 19.11 .14 (fig 7) with a unilateral $\stackrel{\text { जे }}{\stackrel{5}{\circ}}$ right sided cleft of the lip, alveolus, and hard and $\bar{C}$ soft palates. Only the soft palate appears to have $\frac{\bar{\sigma}}{\bar{N}}$ been repaired. He has normal maxillary growth. No $\frac{\rho}{\vec{D}}$ information is available about his parents.

These three family members have been carefully examined to confirm the findings. No lip pits or $\vec{D}$ hypodontia were seen and no associated limb defects were found. General clinical examinations $\vec{\omega}$ were otherwise normal.

Three other first degree relatives are reported to have been affected. III. 4 had a routine dental $x$ ray which showed an alveolar cleft. The lip and palate $\%$ are intact. Her mother had a termination of preg- $\omega$ nancy at four months and the fetus (III.2) is $\infty$ reported to have had a cleft lip. No other details are $\mathrm{o}$ available. II.3, who is now 72 years of age, was not formally examined but was born with bilateral cleft $\vec{c}$ lip and palate. She is said to be in good health and no lip pits have ever been noticed by her family.

\section{Discussion}

The higher incidence of cleft lip and palate in first degree relatives of affected probands is well $\bar{\partial}$ recognised. ${ }^{12}$ Theories to explain these observed findings are more controversial, but in general they $\mathbb{\perp}$ involve both genetic and environmental influences. $\overrightarrow{\vec{P}}$

The multifactorial threshold model championed $\frac{0}{3}$ by Carter $e t a^{1}$ suggests the existence of several influential gene loci interacting with environmental factors and the sex of the person. Woolf, ${ }^{3}$ too, found this explanation to fit his family studies in Utah. Other workers ${ }^{4}$ have proposed a single gene locus with multiple environmental agents acting on the 3 . fetus at different stages of gestation.

The familial occurrence of cleft lip and palate is 3 difficult to explain by simple Mendelian inheritance $\mathrm{O}$ alone. The offspring risk of affected probands is roughly equal to the sib risk, which makes autoso- $\frac{D}{2}$ mal recessive inheritance unlikely. A dominant gene acting alone would not explain the lower incidence $\mathcal{N}$ of cleft lip and palate in second and third degree $N$ relatives compared to that in first degree relatives. N Carter $e a^{1}$ also pointed out that a single gene locus $\omega$ would have to have a very high mutation rate to maintain the incidence of $1 / 1000$ despite previously reduced fertility with cleft lip and palate. Nevertheless, there are autosomal dominantly inherited syndromes in which cleft lip and palate are predominant features.

In any study pooling data from many families, it $\frac{\stackrel{\rho}{\Phi}}{\Phi}$ can also be difficult to detect the rare family where a을 single gene mutation is operating within a popula- 
tion where the low but significantly increased recurrence risks in relatives are the result of multifactorial influences.

Most of the large studies have attempted to exclude cleft lip and palate as part of a known syndrome. The most difficult to exclude clinically among the dominantly inherited syndromes is Van der Woude's syndrome. The findings can be subtle and careful examination is required to exclude the presence of lower lip fistulae. They are present in $80 \%$ of gene carriers. ${ }^{5}$ Hypodontia can also be a feature but is not specific.

Examination must also include the popliteal fossa for webs, hands and feet for syndactyly, and genitalia for hypoplasia, which are associated with clefts in the popliteal web syndrome. The EEC syndrome includes ectrodactyly and ectodermal dysplasia, which are obvious clinically. Other dominantly inherited syndromes to be excluded are the oral-facial-digital type I and Rapp-Hodgkin syndromes, which are both associated with characteristic facial features and delayed development. Inherited chromosomal anomalies can be excluded.

The families described are therefore unusual. The linear pattern of inheritance of cleft lip and palate through three and probably four generations in these families is hard to explain by multifactorial models and autosomal dominant inheritance is strongly suggested. Under the simple multifactorial model, the expected frequency of cleft lip and palate in three generations among affected families would be no higher than 1 in 800 , and in four generations no higher than 1 in 20000 . The pattern of inheritance in family 1 does not exclude an $\mathrm{X}$ linked locus, but this seems unlikely as there was no difference in severity in the sexes.

Despite detailed examination, no associated clinical features could be found to assign a known syndromic label. Van der Woude's syndrome is unlikely in view of the clear absence of lip pits in all six persons examined. Once the Van der Woude locus is mapped, it may well be possible to exclude involvement of this locus in these families formally by linkage analysis.
Few large pedigrees with cleft lip and palate have been described in detail. Woolf ${ }^{6}$ from his work in Utah reported the occasional family with multiple affected subjects and suggested the presence of a rare dominant mutant gene. Recently, Eiberg et $\mathrm{al}^{7}$ have taken 58 pedigrees suggestive of dominant inheritance of non-syndromic cleft lip and palate, although no pedigree details are given, and have found linkage to the blood clotting factor XIIIA on chromosome 6 with lod scores of 3.66 at $\theta=0$ in males and $\theta=0.26$ in females. The work is yet to be substantiated, but does suggest the existence of a significant single gene for cleft lip and palate, at least in some families. This hypothesis is further supported by families such as those reported here, which will prove important once candidate gene probes exist or there are clues as to the location of genes with major influence on cleft lip and palate.

We would like to thank Miss Jo Bramfitt for typing the manuscript. Dr Temple is funded by the Duchenne Muscular Dystrophy Group.

\section{References}

1 Carter CO, Evans K, Coffey R, Fraser Robers JA, Buck A, Fraser Roberts M. A three generation family study of cleft lip with or without cleft palate. J Med Genet 1982;19:246-61.

2 Fogh-Anderson P. Inheritance of harelip and cleft palate. Copenhagen: Busck, 1942.

${ }^{3}$ Woolf CM. Congenital cleft lip. A genetic study of 496 propositi. J Med Genet 1971;8:65-83.

4 Melnick M, Bixler D, Fogh-Anderson P, Conneally PM. Cleft lip \pm cleft palate: an overvicw of the literature and an analysis of Danish cases born between 1941 and 1968. Am J Med Genet 1980;6:83-97.

5 Schinzel A, Klausler M. The Van der Woude syndrome (dominantly inherited lip pits and clefts). J Med Genet 1986;23: 291-4.

6 Woolf CM. Woolf RM, Broadbent TR. A genetic study of cleft lip and palate in Utah. Am J Hum Genet 1963;15:209-15.

${ }^{7}$ Eiberg H. Bixler D, Nielson S, Conneally PM, Mohr J. Suggestion of linkage of a major locus for nonsyndromic orofacial cleft with F13A and tentative assignment to chromosome 6. Clin Genet 1987:32:129-32.

Correspondence to Dr K Temple, Department of Paediatric Genetics, Institute of Child Health, 30 Guilford Street, London WC1N 1EH. 